Part of Journal of Research of the National Bureau of Standards, Volume 25, October 1940

\title{
CALIBRATION OF THERMOCOUPLES AT LOW TEMPERATURES
}

\author{
By Russell B. Scott
}

\section{ABSTRACT}

Descriptions are given of apparatus and methods used at the National Bureau of Standards for the calibration of thermocouples between $0^{\circ}$ and $-190^{\circ} \mathrm{C}$. Descriptions are given of (1) a cryostat for maintaining very constant temperatures in the range $0^{\circ} \mathrm{C}$ to $-170^{\circ} \mathrm{C},(2)$ a convenient and accurate procedure for the realization of the equilibrium sublimation temperature of carbon dioxide using commercial solid $\mathrm{CO}_{2}$, (3) a method of preparing pure oxygen for vaporpressure thermometers, and (4) an improved apparatus for calibrating resistance thermometers and thermocouples at the oxygen boiling point. A reference table for copper-constantan thermocouples is given. Curves are shown representing the deviations from the table of a number of thermocouples calibrated at the National Bureau of Standards. These curves, which represent the behavior of a number of thermocouples from different sources, constitute the basis for a discussion of the relation between the accuracy obtainable with a copper-constantan thermocouple and the number and positions of the calibration points.

\section{CONTENTS}

Page.

I. Introduction

II. Calibration by comparison with a platinum resistance thermometer.- 460

III. Reference table for copper-constantan thermocouples_... 463

IV. Calibration at fixed points

1. $\mathrm{CO}_{2}$ point

2. Oxygen boiling point

V. Accuracy obtainable with copper-constantan thermocouples....... 472

VI. Summary

\section{INTRODUCTION}

Although the platinum resistance thermometer is used to define the International Temperature Scale in the range $0^{\circ}$ to $-190^{\circ} \mathrm{C}$, copper-constantan thermocouples are also extensively used for temperature measurements in this range. A thermocouple may be calibrated either by direct comparison with a standard platinum resistance thermometer at several temperatures, or by determining its electromotive force (emf) at a number of fixed points, the temperatures of which are known on the International Temperature Scale. After having obtained values for the emf and temperature at a number of calibration points, the process of interpolating, to obtain a continuous temperature-emf relation over the whole range, is greatly facilitated by the use of a table giving the emf of a representative thermocouple. Such a table for a copper-constantan thermocouple is given in this paper. It is the purpose of this paper to describe, first, the apparatus and methods used at this Bureau to calibrate thermocouples by direct comparison with a platinum resistance ther- 
mometer, and then to show how, with considerably simpler apparatus, certain fixed points may be used to obtain a calibration of sufficient accuracy for most purposes.

\section{CALIBRATION BY COMPARISON WITH A PLATINUM RESISTANCE THERMOMETER}

The strain-free platinum resistance thermometer is used as the standard temperature-measuring instrument for the calibration of thermocouples in the range $0^{\circ}$ to $-190^{\circ} \mathrm{C}$, although at temperatures near the normal boiling point of oxygen $\left(-182.97^{\circ} \mathrm{C}\right)$ the oxygen vapor-pressure thermometer may be used. At the low end of this range a bath of liquid air or liquid oxygen boiling at atmospheric pressure is used to cool a copper comparison block into which the thermocouple junction and the standard thermometer are inserted. For calibrations in the temperature range above $-170^{\circ} \mathrm{C}$, a cryostat ${ }^{i}$ which automatically maintains the desired constant temperature in a stirred liquid bath is used. A vertical section of the cryostat is shown in figure 1. The refrigeration is supplied by liquid air in the outer Dewar flask, $C$, and controlled by varying the gas pressure between the walls of the inner Dewar, $D$, which contains the constant-temperature bath. This method of applying and controlling the refrigeration has been used by Rothe ${ }^{2}$ and by Keyes, Taylor, and Smith. ${ }^{3}$ The gas pressure is adjusted through tube $M$, which connects with a high-vacuum system.

The cryostat liquid is circulated by a propeller, $I$, which revolves in the bottom of a Bakelite tube, $P$, in such a direction that the liquid passes up through the inside of the Bakelite tube and down the outside. To permit this circulation, four windows, $B, 2.5 \mathrm{~cm}$ long, were cut in the Bakelite tube. In order that the liquid at the surface shall be drawn away as its temperature is changed by the heat conducted in from the warm exterior, the liquid level is kept below the top of the windows. The propeller is driven at a speed of about 400 revolutions per minute by a system of three gears, $H$, driven by a shaft, $K$, connected to a motor through a flexible shaft, $O$. Three vertical vanes, $F$, support the bearings for the propeller and idlergear shafts, and improve the circulation by preventing a whirling motion of the liquid above and below the propeller. Stainless-steel pinions and a Bakelite idler gear were found to be satisfactory. Monel-metal shafts turning in high-lead ( 85 percent) babbitt bearings were used. Since the cryostat liquids are poor lubricants, powdered graphite was rubbed on the bearing surfaces before assembling the stirrer. Special bearing materials consisting of a mixture of graphite in metal may be more satisfactory.

The heating coil, $J$, shown by dotted lines, is made of No. 22 AWG Ni-Cr alloy wire ( $80 \mathrm{Ni}-20 \mathrm{Cr}$ ) and has a resistance of about $30 \mathrm{ohms}$. The bare wire is wound bifilarly on a form which fits the stirrer tube, $P$, its ends terminating at the top in leads, $Q$, which connect to the power supply through the thermoregulator. The form is made from a Bakelite tube by cutting wide slots in its walls, leaving six strips about $1 \mathrm{~cm}$ wide and supporting rings at the ends and center. Lag in the heater is reduced by this support and manner

1 Scott and Brickwedde, BS J. Research 6, 401 (1931) RP284.

2 Rothe, Z. Instrumentenk. 22, 14 (1902).

\& Keyes, Taylor, and Smith, J. Math. Phys. 1, 211 (1922). 


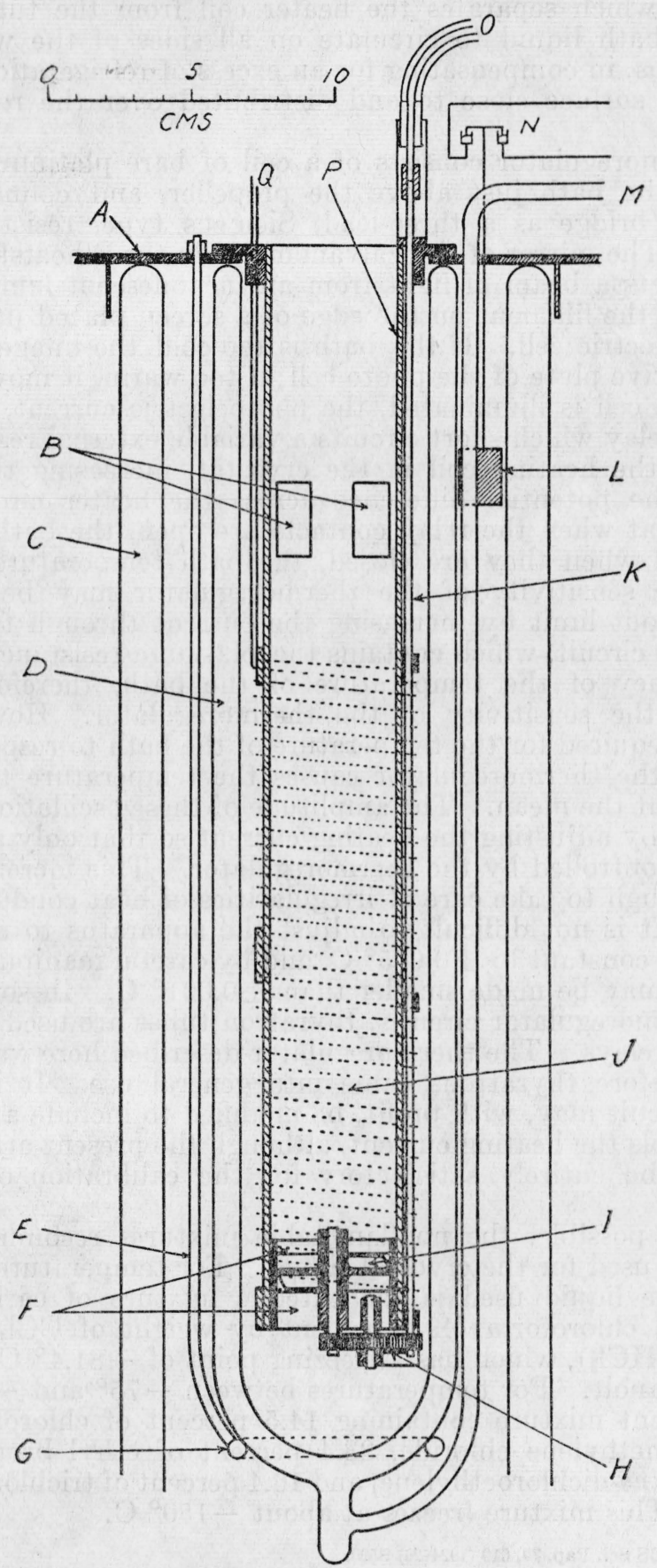

FIGURE 1.-Vertical section of the cryostat. 
of winding which separates the heater coil from the tube, $P$, and allows the bath liquid to circulate on all sides of the wire. It is advantageous, in compensating for an excess of refrigeration, to have the heating surface close to and distributed over the refrigerating surface.

The thermoregulator consists of a coil of bare platinum wire immersed in the bath just above the propeller, and connected to a Wheatstone bridge as a three-lead, Siemens type, resistance thermometer. The mirror of the galvanometer in the Wheatstone-bridge circuit reflects a beam of light from an incandescent lamp, forming an image of the filament on the edge of a screen placed just in front of a photoelectric cell. If the bath is too cold, the image moves on to the sensitive plate of the photo cell; if too warm, it moves off.

When the cell is illuminated, the photoelectric current, amplified, actuates a relay which short circuits a variable external resistance, in series with the heating coil in the cryostat, increasing the heating current. The potential difference across the heater circuit is adjusted so that when the relay contacts are open, the bath is slowly cooling, and when they are closed, the bath temperature is slowly rising. The sensitivity of the thermoregulator may be increased almost without limit by increasing the current through the Wheatstone-bridge circuit, which contains the platinum resistance element. The constancy of the temperature of the bath, therefore, is not limited by the sensitivity of the thermoregulator. However, the finite time required for the temperature of the bath to respond to the demand of the thermoregulator causes the temperature to oscillate slightly about the mean. The amplitude of these oscillations may be made small by adjusting the heating current so that only a small increment is controlled by the thermoregulator. This increment must be large enough to take care of irregularities of heat conduction into the bath. It is not difficult to adjust the apparatus to maintain a temperature constant to $\pm 0.005^{\circ} \mathrm{C}$, and by careful manipulation, the oscillations may be made smaller than $\pm 0.001^{\circ} \mathrm{C}$. In some photoelectric thermoregulator circuits, thyratron tubes are used instead of mechanical relays. The thermoregulator described here was put into operation before thyratrons came into general use. It is possible that this circuit may, with profit, be modified to include a thyratron which controls the heating current, although the present arrangement appears to be entirely satisfactory for the calibration of thermocouples.

As far as possible, the nonflammable mixtures recommended by Kanolt ${ }^{4}$ are used for the cryostat liquid. For temperatures down to $-75^{\circ} \mathrm{C}$, the liquid used is the eutectic mixture of carbon tetrachloride and chloroform (49.4 percent by weight of $\mathrm{CCl}_{4}$ and 50.6 percent of $\mathrm{CHCl}_{3}$ ), which has a freezing point of $-81.4^{\circ} \mathrm{C}$, as determined by Kanolt. For temperatures between $-75^{\circ}$ and $-140^{\circ} \mathrm{C}$, a five-component mixture containing 14.5 percent of chloroform, 25.3 percent of methylene chloride, 33.4 percent of ethyl bromide, 10.4 percent of trans-dichloroethylene, and 16.4 percent of trichloroethylene was used. This mixture freezes at about $-150^{\circ} \mathrm{C}$.

C. W. Kanolt, BS Sci. Pap. 20, 619 (1924-26) \$520. 
At temperatures below $-140^{\circ} \mathrm{C}$ the nonflammable liquids are so viscous that they cannot be readily stirred. For this lower range the liquid used is commercial propane, which is sold for domestic gas heating under various trade names. The propane, which is a gas at atmospheric pressure and room temperature, is compressed into steel cylinders and liquefied at a pressure of about $150 \mathrm{lb} / \mathrm{in}^{2}{ }^{2}$ It may be conveniently liquefied at atmospheric pressure by running it through a copper coil immersed in liquid air. Its boiling point is about $-44^{\circ} \mathrm{C}$, and it remains liquid down to liquid-air temperatures. It is, however, highly flammable, and its use is attended with some danger. Every precaution should be taken to prevent the mixing of liquid air and propane in case the Dewars break. The inner Dewar should be fitted with either a metal liner or a metal jacket if propane is used. If liquid nitrogen is available, it should be used instead of liquid air for the refrigerating liquid.

For the measurement of the emf of the thermocouple a low-range Wenner potentiometer is used. This instrument has two ranges: 0 to $11,000 \mu \mathrm{v}$, in steps of $0.1 \mu \mathrm{v}$; and 0 to $110,000 \mu \mathrm{v}$, in steps of $1 \mu \mathrm{v}$. Switches are provided for reversing simultaneously the potentiometer current and the emf being measured, so as to cancel out spurious emfs in the galvanometer circuit. Also, the leads from the potentiometer to the thermocouple may be shorted at the ice junctions to check the measuring circuit at zero emf.

\section{REFERENCE TABLE FOR COPPER-CONSTANTAN THERMOCOUPLES}

It has been found that the temperature-emf relation for a copperconstantan thermocouple, in the range $0^{\circ}$ to $-190^{\circ} \mathrm{C}$, may be expressed by the equation

$$
E=a t+b t^{2}+c t^{3},
$$

where $E$ is the emf, $t$ the temperature in degrees centigrade, and $a, b$, and $c$ constants. A thermocouple made of carefully selected wire was calibrated at approximately 10-degree intervals over this range of temperatures. The constants $a, b$, and $c$ were computed by the method of least squares. The observed points deviate randomly from the equation so obtained, the average deviation being 0.6 microvolt. As a convenience in calibrating and using thermocouples, table 1 was computed, giving the emf, at 2-degree intervals, and table 2, giving the temperature at intervals of 50 microvolts. This permits an accuracy of interpolation of 0.1 microvolt. Calibrations are made by determining the emf at a few temperatures and plotting deviations from the table. 
Journal of Research of the National Bureau of Standards [Vol.25

TABLE 1.-Reference table for copper-constantan thermocouples

\begin{tabular}{|c|c|c|c|c|c|c|c|c|}
\hline $\begin{array}{c}\text { Tempera- } \\
\text { ture }\end{array}$ & $E$ & $d E / d t$ & $\begin{array}{c}\text { Tempera- } \\
\text { ture }\end{array}$ & $E$ & $d E / d t$ & $\begin{array}{c}\text { Tempera- } \\
\text { ture }\end{array}$ & $\boldsymbol{E}$ & $d E / d t$ \\
\hline${ }^{\circ} \mathrm{C}$ & $\stackrel{\mu v}{0.0}$ & $0^{\mu v /{ }^{\circ} \mathrm{C}}$ & ${ }^{\circ}{ }^{\circ}-66$ & $\stackrel{\mu v}{2327 .} 4$ & $4^{\mu v /}$ & $\begin{array}{l}{ }^{\circ} \mathrm{C} \\
-130\end{array}$ & $\stackrel{\mu \nu}{4136.7}$ & $7^{\mu v / l^{\circ} C}$ \\
\hline-2 & 76.8 & $8^{38.4}$ & -68 & 2391. 0 & $0^{31 .}$ & -132 & 4185. 5 & $5^{24.4}$ \\
\hline-4 & 153. 2 & $2^{38.2}$ & -70 & 2454. 1 & $1^{31 .}$ & -134 & 4233. 8 & $8^{24}$ \\
\hline-6 & 229. 2 & $2^{38.0}$ & -72 & 2516.7 & $7^{31.3}$ & -136 & 4281.5 & $5^{23}$ \\
\hline-8 & 304.8 & 37.8 & -74 & 2579.0 & 31.1 & -138 & 43288 & 23.6 \\
\hline-8 & 304.8 & 37.6 & -84 & 2019.0 & $\begin{array}{l}0 \\
0\end{array}$ & -100 & 9020.8 & 23.4 \\
\hline-10 & 380.1 & $\begin{array}{l}137.4 \\
37\end{array}$ & -76 & 2640.8 & ${ }^{8} 30$. & -140 & 4375.6 & ${ }^{6}$ \\
\hline-12 & 455. 0 & 0 & -78 & 2702.1 & 1 & --142 & 4421. 8 & 8 \\
\hline-14 & 529.5 & & -80 & 2763. 1 & & -144 & 4467.6 & \\
\hline-16 & 603.7 & $7^{37.1}$ & -82 & 2823. 5 & $5^{30.2}$ & -146 & 4512. 9 & 9 \\
\hline-18 & 677.4 & & -84 & 2883. 6 & 6 & -148 & 4557.6 & 6 \\
\hline-20 & 750.8 & 8 & -86 & 2943. 1 & $1^{29.8}$ & -150 & 4601.9 & \\
\hline-22 & 823. 8 & $8^{30.0}$ & -88 & 3002.3 & $3^{29.6}$ & -152 & 4645. 6 & 6 \\
\hline-24 & 896. 3 & $3^{36.3}$ & -90 & 3061.0 & $0^{29.3}$ & -154 & 4688. 8 & $8^{21.6}$ \\
\hline-26 & 968.5 & $5^{36.1}$ & -92 & 3119.2 & $2^{29.1}$ & -156 & 4731. 4 & $4^{21.3}$ \\
\hline-28 & 1040. 3 & 35.9 & -94 & 3176.9 & $9^{28.9}$ & -158 & 4773. 7 & $7^{21.1}$ \\
\hline-20 & 1111 & 35.7 & -06 & 20 & 28.7 & & & 20.8 \\
\hline-30 & 1111.8 & & -96 & 3234. 3 & 3 & -160 & 4815. 4 & $\begin{array}{l}4_{20.6} \\
\end{array}$ \\
\hline-32 & 1182.8 & & -98 & 3291. 1 & 1 & -162 & 4.856. 6 & 6 \\
\hline-34 & 1253. 4 & & -100 & 3347.5 & $5^{28.2}$ & -164 & 4897. 2 & 2 \\
\hline-36 & 1323. 6 & 6 & -102 & 3403.4 & 4 & -166 & 4937. 3 & 3 \\
\hline-38 & 1393. 4 & & -104 & 3458.9 & & -168 & 4976. 9 & 9 \\
\hline-40 & 1462.8 & & -106 & 3513. 9 & & -170 & 5015. 9 & \\
\hline-42 & 1531. 8 & & -108 & 3568.4 & 4 & -172 & 5054. 5 & 5 \\
\hline-44 & 1600.4 & & -110 & 3622.5 & $5^{27}$ & -174 & 5092.5 & 5 \\
\hline-46 & 1668. 6 & $6^{34.1}$ & -112 & 3676. 1 & $1^{26 .}$ & -176 & 5129. 9 & 9 \\
\hline-48 & 1736. 3 & $3^{33}$ & -114 & 3729. 2 & $2^{26.6}$ & -178 & 5166.9 & $9^{18.5}$ \\
\hline-50 & 1803. 7 & 33.7 & -116 & 3781.8 & $8^{26 .}$ & -180 & 5203.3 & $3^{18.2}$ \\
\hline-52 & 187 & 33 & & 0 & 26.1 & & & 17.9 \\
\hline-02 & 1080.0 & 33. & 118 & 3834.0 & 9 & -182 & 5239. 1 & $\begin{array}{l}1 \\
17\end{array}$ \\
\hline-54 & 1937. 2 & & -120 & 3885.6 & & -184 & 5274.4 & \\
\hline-56 & 2003. 3 & & -122 & 3936.8 & 8 & -186 & 5309. 2 & 2 \\
\hline-58 & 2068. 9 & & -124 & 3987.5 & 5 & -188 & 5343. 4 & \\
\hline-60 & 2134. 2 & & -126 & 4037.8 & & -190 & 5377. 1 & \\
\hline-62 & 2199.0 & & -128 & 4087. 5 & 5 & -192 & 5410. 2 & \\
\hline-64 & 2263.4 & & & & & & & \\
\hline & & 32.0 & & & & & & \\
\hline
\end{tabular}


TABLE 2.-Reference table for copperco-nstantan thermocouples

\begin{tabular}{|c|c|c|c|c|c|c|c|c|}
\hline$E$ & Temperature & $d t / d E$ & $E$ & Temperature & $d / d E$ & $E$ & Temperature & $d t / d E$ \\
\hline${ }^{\mu v} 0$ & $\begin{array}{l}{ }^{\circ} C \\
0.0\end{array}$ & ${ }^{\circ} C_{l} \mu v$ & $\stackrel{\mu v}{1800}$ & 49. ${ }^{\circ} 890$ & ${ }^{\circ} C / \mu v$ & $\begin{array}{l}\mu v \\
3600\end{array}$ & $\begin{array}{c}\circ{ }^{\circ} C \\
\text { 109. } 166\end{array}$ & ${ }^{\circ} \mathrm{Cl \mu v}$ \\
\hline 50 & 1. 302 & & 1850 & 51. 382 & & 3650 & 111.025 & 0.03 \\
\hline 100 & 2. 607 & & 1900 & 52. 881 & & 3700 & 112. 900 & 03 \\
\hline 150 & 3. 917 & .02620 & 1950 & 54. 388 & .03014 & 3750 & 114. 790 & .03780 \\
\hline 200 & 5. 231 & & 2000 & 55. 901 & & 3800 & 116. 696 & \\
\hline 250 & 6. 549 & & 2050 & 57. 422 & & 3850 & 118. 619 & 6 \\
\hline 300 & 7. 872 & .026 & 2100 & 58. 950 & .03 & 3900 & 120.560 & . 038 \\
\hline 350 & 9. 199 & .02654 & 2150 & 60.486 & .03072 & 3950 & 122.518 & .03916 \\
\hline 400 & 10. 530 & & 2200 & 62.030 & & 4000 & 124. 495 & \\
\hline 450 & 11. 866 & & 2250 & 63.582 & & 4050 & 126. 491 & \\
\hline 500 & 13. 206 & $.0268 \mathrm{r}>\mathrm{C}$ & 2300 & 65. 142 & & 4100 & 128. 507 & .040 \\
\hline 550 & 14. 551 & & 2350 & 66. 710 & & 4150 & 130. 543 & \\
\hline 600 & 15. 901 & & 2400 & 68. 286 & & 4200 & 132.600 & \\
\hline 650 & 17. 255 & & 2450 & 69. 871 & & 4250 & 134. 678 & \\
\hline 700 & 18. 615 & & 2500 & 71. 464 & & 4300 & 136. 780 & \\
\hline 750 & 19. 979 & & 2550 & 73. 067 & & 4350 & 138. 905 & \\
\hline 800 & 21. 348 & & 2600 & 74. 679 & & 4400 & 141. 054 & \\
\hline 850 & 22. 722 & & 2650 & 76. 300 & & 4450 & 143. 229 & .043 \\
\hline 900 & 24. 101 & & 2700 & 77. 930 & & 4500 & 145.430 & \\
\hline 950 & 25.485 & & 2750 & 79.570 & & 4550 & 147. 659 & \\
\hline 1000 & 26. 875 & .027 & 2800 & 81.220 & & 4600 & 149.916 & $.045>>15$ \\
\hline 1050 & 28. 270 & . 02790 & 2850 & 82.880 & .033 & 4650 & 152. 203 & .04574 \\
\hline 1100 & 29. 670 & & 2900 & 84.550 & & 4700 & 154. 522 & .046 \\
\hline 1150 & 31.076 & & 2950 & 86.231 & & 4750 & 156.873 & \\
\hline 1200 & 32.487 & .0 & 3000 & 87.923 & 0 & 4800 & 159. 259 & .04 \\
\hline 1250 & 33. 904 & & 3050 & 89.626 & & 4850 & 161. 680 & .0 \\
\hline 1300 & 35. 327 & & 3100 & 91. 340 & & 4900 & 164. 140 & \\
\hline 1350 & 36 & & 3150 & 93.065 & & 4950 & 166. 639 & $.04>>$ \\
\hline 1400 & 38.190 & .0 & 3200 & 94. 803 & & 5000 & 169. & .05 \\
\hline 1450 & 39.630 & 02880 & 3250 & 96.553 & 0 & 5050 & 171 & .051 \\
\hline 1. & & .028 & 3300 & 88.315 & .035 & & & .052 \\
\hline & & .0 & & 10000 & 0 & & & .05 \\
\hline 1550 & 42.529 & & 3350 & 100.089 & & 5150 & 177.083 & \\
\hline 1600 & 43. 988 & & 3400 & 1.01. 877 & & 5200 & 179. 820 & \\
\hline 1650 & 45. 454 & & 3450 & 103.679 & & 5250 & 182. 614 & \\
\hline 1700 & 46. 926 & & 3500 & 105. 494 & & 5300 & 185. 469 & \\
\hline 1750 & 48.405 & & 3550 & 107. 323 & & 5350 & 188. 389 & \\
\hline & & & & & & 5400 & 191. 379 & 5980 \\
\hline
\end{tabular}


Deviation curves for a number of copper-constantan thermocouples are shown in figure 2. Each of these curves represents from 4 to 10 observed points. This is more points than are necessary for a calibration, but in this case closer spacing of the observations was needed so that irregularities in the deviation curves might be detected. Ordinates are emf of thermocouple minus emf from table 1. The observed emf is used as abscissa, because the deviation curves so obtained are more nearly linear than those obtained using abscissa to represent temperature. The deviation curves of thermocouples sent in for calibration are distributed almost equally above and below the axis. The curves are smooth, of slight curvature, and have no inflection points. Also shown in the figure are deviation curves of two other copper-constantan thermocouple tables, as given by Adams ${ }^{5}$ and Southard and Andrews, ${ }^{6}$ labeled $A$ and $S$, respectively.

Adams' table was calculated from the equation

$$
E=a t-b\left(1-e^{-c t}\right),
$$

the constants of which were determined by calibrations at the freezing point of mercury, the sublimation temperature of carbon dioxide, and the boiling point of oxygen. In view of the fact that when Adams' table was computed apparatus was not available for careful tests between the calibration points, his success is remarkable. It has been found, however, that most of the thermocouples calibrated at the National Bureau of Standards show somewhat more regular deviation curves from table 1 than from Adams' table. This is probably due to a difference in the composition of the constantan used by Adams, which affected the shape of the temperature-emf curve, and which had little effect on the magnitude of the emf produced. The table by Southard and Andrews was constructed from calibrations of a thermocouple at 15 temperatures between $0^{\circ}$ and $-190^{\circ} \mathrm{C}$. The shape of the curve is almost the same as that represented by table 1 , but the values of emf are considerably lower than the average of the thermocouples tested here. The thermocouple wires included in these tests range in size from No. 22 to No. $36 \mathrm{AWG}$, sizes which are ordinarily used at low temperatures.

\section{CALIBRATION AT FIXED POINTS}

\section{1. $\mathrm{CO}_{2}$ POINT}

The deviation curves of all the thermocouples that have been calibrated recently at the National Bureau of Standards are so nearly straight that a determination of the emf at the normal sublimation temperature of carbon dioxide $\left(-78.51^{\circ} \mathrm{C}\right.$ on the International Scale) is sufficient to establish the temperature-emf relation in the range $0^{\circ}$ to $-90^{\circ} \mathrm{C}$. An accuracy of \pm 2 microvolts may be obtained by plotting the deviation curve in the manner shown in figure 2 and drawing a straight line through the observed point and the origin. Since solid carbon dioxide is now a widely distributed commercial product, many laboratories should find it useful as a means of realizing the normal sublimation temperature as a calibration point or as a check point for thermometers and thermocouples. However, certain

S Symposium on Pyrometry (A. I. M. M. E.) p. 165 (1920), Int. Crit. Tables 1, 58 (1926).

- J. Franklin Inst. 207, 323 (1929). 


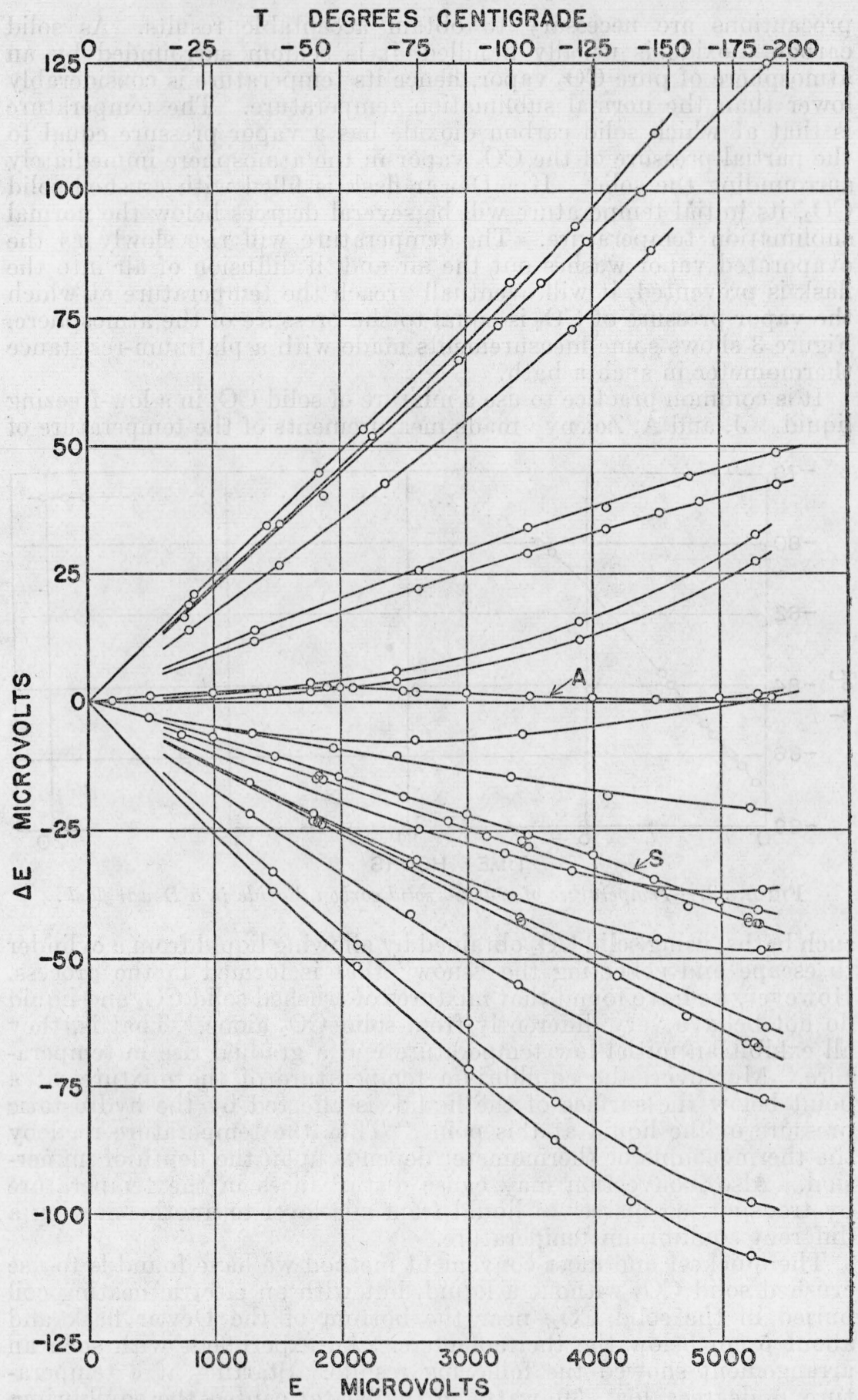

Figure 2.-Differences between the calibrations of some copper-constantan thermocouples and the values given in table 1. 
precautions are necessary to obtain acceptable results. As solid carbon dioxide is usually handled, it is seldom surrounded by an atmosphere of pure $\mathrm{CO}_{2}$ vapor, hence its temperature is considerably lower than the normal sublimation temperature. The temperature is that at which solid carbon dioxide has a vapor pressure equal to the partial pressure of the $\mathrm{CO}_{2}$ vapor in the atmosphere immediately surrounding the solid. If a Dewar flask is filled with crushed solid $\mathrm{CO}_{2}$, its initial temperature will be several degrees below the normal sublimation temperature. The temperature will rise slowly as the evaporated vapor washes out the air and, if diffusion of air into the flask is prevented, it will eventually reach the temperature at which the vapor pressure of $\mathrm{CO}_{2}$ is equal to the pressure of the atmosphere. Figure 3 shows some measurements made with a platinum-resistance thermometer in such a bath.

It is common practice to use a mixture of solid $\mathrm{CO}_{2}$ in a low-freezing liquid. J. and A. Zeleny ${ }^{7}$ made measurements of the temperature of

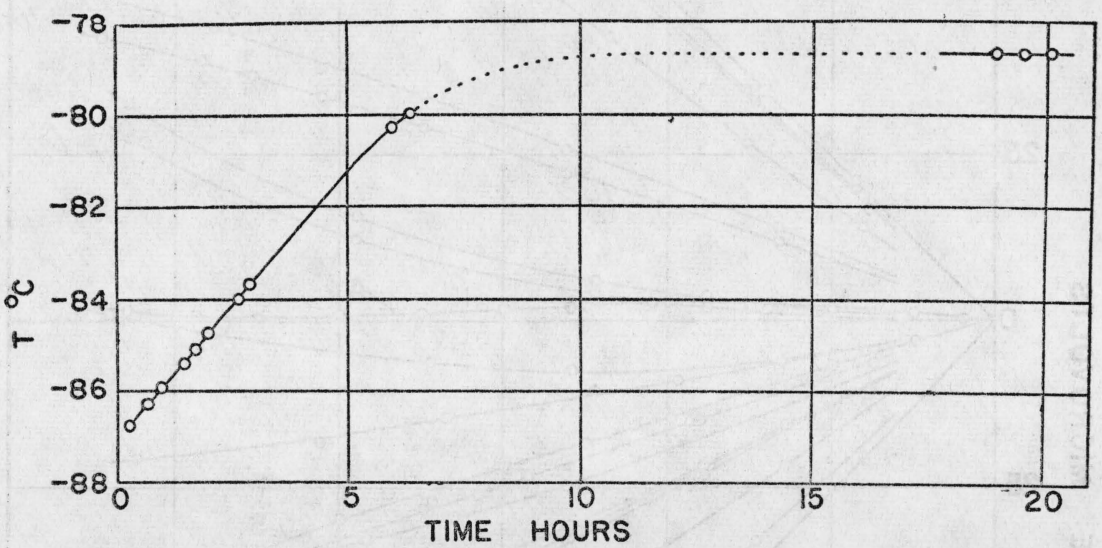

Figure 3.-Temperature of crushed solid carbon dioxide in a Dewar flask.

such baths, using solid $\mathrm{CO}_{2}$ obtained by allowing liquid from a cylinder to escape and collecting the "snow" that is formed in the process. However, we have found that mixtures of crushed solid $\mathrm{CO}_{2}$ and liquid do not behave very differently from solid $\mathrm{CO}_{2}$ alone. That is, they all exhibit an initial low temperature and a gradual rise in temperature. Moreover, the equilibrium temperature of the mixture, at a point below the surface of the liquid, is affected by the hydrostatic pressure of the liquid at this point. Thus the temperature read by the thermocouple or thermometer depends upon the depth of immersion. Also, convection may cause disturbances in the temperature by transporting masses of liquid from one level to another having a different equilibrium temperature.

The quickest and most convenient method we have found is to use crushed solid $\mathrm{CO}_{2}$ without a liquid, but with an electric heating coil buried in the solid $\mathrm{CO}_{2}$, near the bottom of the Dewar flask and about $5 \mathrm{~cm}$ below the thermometers. An experiment with such an arrangement showed the following results. Starting at a temperature 6 degrees low, 30 watts in the heater caused the equilibrium temperature to be attained in 12 minutes. Further heating caused

7 John Zeleny and Anthony Zeleny, Phys. Rev. [1] 23, 308 (1906). 
no change in temperature. The heat input was then reduced and left at 7 watts so as to keep a stream of $\mathrm{CO}_{2}$ vapor flowing out of the flask to prevent air from diffusing in. Readings were then taken with two platinum-resistance thermometers in the bath, and with the barometer in the same room. The temperature of the solid carbon dioxide was calculated from its vapor pressure (barometric) by means the equation

$$
\log _{10} p=9.81137-\frac{1349}{t+273.16},
$$

where $t$ is in degrees centigrade and $p$ is in millimeters of $\mathrm{Hg}$. The constants in this equation were chosen to fit the results of Meyers: and Van Dusen ${ }^{8}$ in the neighborhood of the normal sublimation. temperature. The results are given in table 3. Other tests with just one thermometer have given similar results. From these results it appears that the temperature of equilibrium between solid and gaseous carbon dioxide may be attained by this method, with an accuracy of about $0.01^{\circ} \mathrm{C}$. Judging from the evidence available, it appears unlikely that impurities found in commercial solid $\mathrm{CO}_{2}$ will affect the temperature sufficiently to invalidate this conclusion.

TABLE 3.-Sublimation temperature of $\mathrm{CO}_{2}$

\begin{tabular}{|c|c|c|c|}
\hline $\begin{array}{c}\text { Vapor } \\
\text { pressure } \\
\text { (barometric) }\end{array}$ & $\begin{array}{c}\text { Temperature } \\
\text { Calculated by } \\
\text { vapor-pressure } \\
\text { equation }\end{array}$ & $\begin{array}{c}\text { Resistance } \\
\text { thermometer } \\
\text { I }\end{array}$ & $\begin{array}{c}\text { Resistance } \\
\text { thermometer } \\
\text { II }\end{array}$ \\
\hline$\underset{754.44}{m m}$ & -78.604 & -78.598 & -78.593 \\
\hline${ }^{\circ} \mathrm{Cg}$ & ${ }^{\circ} \mathrm{C}$ & ${ }^{\circ} \mathrm{C}$ \\
\hline
\end{tabular}

\section{OXYGEN BOILING POINT}

The deviation curves, figure 2 , indicate that the boiling point of oxygen $\left(-182.97^{\circ} \mathrm{C}\right)$, together with the sublimation point of $\mathrm{CO}_{2}$, might be used to obtain a fair calibration curve for a copper-constantan thermocouple over the entire range of $0^{\circ}$ to $-190^{\circ} \mathrm{C}$. However, the apparatus necessary for the realization of the oxygen boiling point is more elaborate than that used for the $\mathrm{CO}_{2}$ point. Commercial oxygen usually contains enough nitrogen to make the boiling temperature uncertain. Even if the oxygen supply is pure, the liquid oxygen may become contaminated with atmospheric nitrogen by diffusion of air to the liquid surface. Also, the liquid may superheat, in which case the temperature of the liquid in the interior of the bath may be a degree or more above the temperature of the surface. Thus the temperature of a bath of liquid commercial oxygen cannot be determined simply by reading the barometer and applying a vaporpressure equation, as was done in the case of solid carbon dioxide. A satisfactory method is to use a small quantity of pure oxygen in a vapor-pressure thermometer to determine the temperature of the bath.

It has been found that oxygen of sufficient purity for use in vaporpressure thermometers may be prepared by the thermal decomposition

${ }^{8}$ C. H. Meyers and M. S. Van Dusen, The vapor pressure of liquid and solid carbon dioxide, BS J. Research 10, 381 (1933) RP538. 
of potassium permanganate. The procedure was as follows: The salt was outgassed under high vacuum for 17 hours at a temperature of $160^{\circ}$ to $175^{\circ} \mathrm{C}$ to remove adsorbed air. The temperature was then raised slowly while continuing the pumping until, in about 2 hours, the oxygen was coming off at a moderate rate at a temperature of about $215^{\circ} \mathrm{C}$. After discarding the first oxygen generated at this temperature, the rest was collected by allowing it to condense into a bulb surrounded by liquid air. The collection was stopped when the salt reached a temperature of about $235^{\circ} \mathrm{C}$.

A $4,500 \mathrm{~cm}^{3}$ (gas) sample of oxygen thus obtained was distilled in a still with a rectifying column. The distillate was divided into 3 fractions of $300,4,000$ and $200 \mathrm{~cm}^{3}$. The vapor pressures of these three fractions were compared in an apparatus equipped with a differential manometer filled with apiezon oil. The maximum difference observed was less than $0.02 \mathrm{~mm} \mathrm{Hg}$ at $-183^{\circ} \mathrm{C}$. This indicates that there was no impurity present in the original sample in sufficient quantity to affect the vapor pressure appreciably. The vapor pressure of the oxygen prepared from potassium permanganate was also compared with that of a sample prepared by the electrolytic decomposition ${ }^{9}$ of a carefully purified solution of barium hydroxide. It was necessary to use mercury manometers in this comparison, because the latter sample was sealed up in a vapor-pressure thermometer. The smallest detectable difference was, in this case, $0.1 \mathrm{~mm} \mathrm{Hg}$. No difference was observed.

Several designs of oxygen vapor-pressure thermometers and baths have been used in the various national standardizing laboratories. The following is a description of an arrangement now in use at the National Bureau of Standards. In figure $4, F$ is a massive copper cylinder immersed in a bath of liquid commercial oxygen. The oxygen from a high-pressure cylinder is liquefied by passing it through a coil of copper tubing immersed in liquid air. The copper cylinder is supported from above by the thin-walled $(0.28 \mathrm{~mm})$ Monel cylinder, $E$, which has openings in the sides to permit circulation of the liquid oxygen. The central cavity, $G$, contains a small quantity of pure liquid oxygen, prepared from $\mathrm{KMnO}_{4}$ according to the method given above. The vapor pressure exerted by this pure oxygen is transmitted to the manometer, $A$, through the tube, $C$, which is an alloy of copper and nickel. The protecting tube, $D$, keeps the bath from coming in contact with the pressure-transmitting tube, $C$, so that cold spots on $C$ are avoided. Thus the vapor pressure, as read by the manometer, is that which corresponds to the temperature of the copper cylinder, and it is not affected by a possible cold region near the suriace of the bath. In order to prevent superheating of the bath, a slow stream of gaseous oxygen from a cylinder is admitted through tube, $B$, which extends to the bottom of the Dewar flask. The copper cylinder also contains wells into which thermocouples or resistance thermometers may be inserted. The copper-nickel tube, $C$, is connected to the Pyrex glass of the manometer by soldering it to the copper end of a Housekeeper ${ }^{10}$ seal. The inside diameter of the manometer tubing is $1 \mathrm{~cm}$. The positions of the mercury menisci are observed by means of a mirror-backed glass scale mounted in contact with the manometer tubes. The precision of measurement is about $0.1 \mathrm{~mm}$. The

Shepherd, Weaver, and Pickering, J. Research NBS 22, 301 (1939) RP1182.

10 J. Am. Inst. Elec. Eng. 42, 954 (1923). 

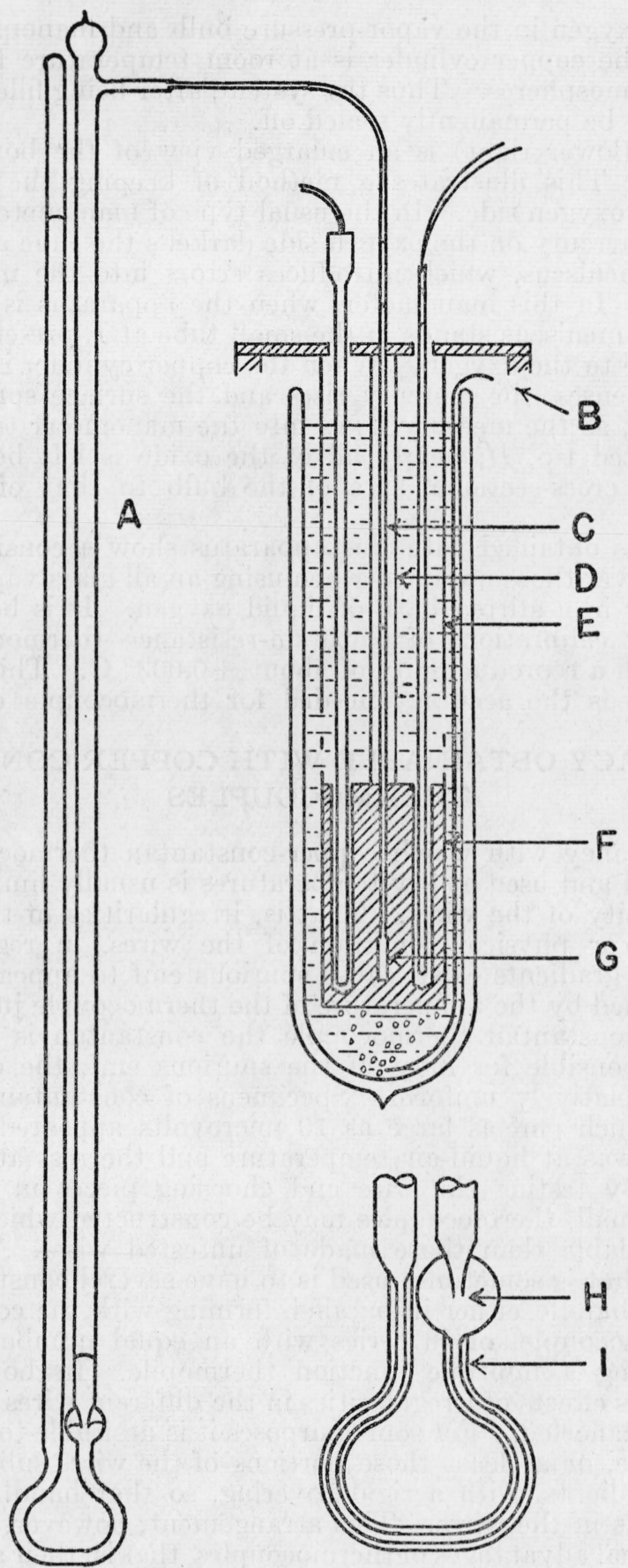

FIgURE 4.-Apparatus for calibration of thermometers and thermocouples at boiling point of oxygen. 
amount of oxygen in the vapor-pressure bulb and manometer is such that when the copper cylinder is at room temperature the pressure is about 3 atmospheres. Thus the system, after being filled with pure oxygen, may be permanently sealed off.

Figure 4 (lower right) is an enlarged view of the bottom of the manometer. This illustrates a method of keeping the manometer clean on the oxygen side. In the usual type of manometer the oxidation of the mercury on the oxygen side darkens the tube and causes a misshapen meniscus, which introduces errors into the measurement of pressure. In this manometer, when the apparatus is not in use, the mercury meniscus stands in the small tube at $I$, presenting only a small surface to the oxygen. When the copper cylinder is cooled and oxygen condenses, the mercury rises and the surface spreads in the bulb so that, as the mercury flows into the manometer tube through the constricted tip, $H$, nearly all of the oxide is left behind. The ratio of the cross-sectional area of the bulb to that of the tip is about 100 .

The results obtained with this apparatus show a considerable improvement over those obtained when using an all-glass vapor-pressure thermometer in a stirred bath of liquid oxygen. It is believed that oxygen-point calibrations of platinum-resistance thermometers may be made with a reproducibility of about $\pm 0.003^{\circ} \mathrm{C}$. This, of course, greatly exceeds the accuracy needed for thermocouple calibrations.

\section{ACCURACY OBTAINABLE WITH COPPER-CONSTANTAN THERMOCOUPLES}

The accurancy with which copper-constantan thermocouples may be calibrated and used at low temperatures is usually limited by lack of homogeneity of the wires. That is, irregularities in the chemical composition or physical condition of the wires, in regions where temperature gradients exist, cause spurious emf to appear which are not determined by the temperature of the thermocouple junction. In the copper-constantan thermocouple the constantan is usually the element responsible for most of the spurious emf, the copper as a rule being relatively uniform. Specimens of constantan have been found in which emf as large as 10 microvolts appeared, when part of the wire was at liquid-air temperature and the rest at room temperature. By testing the wire and choosing pieces in which such effects are small, thermocouples may be constructed which are much more dependable than those made of untested wire. Another improvement that is sometimes used is to have several constantan wires in the same bundle, either in parallel, forming with the copper wire a single thermocouple, or in series with an equal number of copper wires, forming a multiple junction thermopile. In both of these arrangements effects of irregularities in the different wires will usually be partially canceled. For some purposes it is desirable to protect the thermocouple, or at least those portions of the wires subject to temperature gradients, with a rigid covering, so that handling will not set up strains in the wires. This arrangement, however, defeats one of the principal advantages of thermocouples, that is, their adaptability for use in an intricate apparatus from which the wires must be brought out through a devious path. A few thermocouples of special construction, in which several selected constantan wires were used, 
have been calibrated at low temperatures at the National Bureau of Standards. Although experience with such thermocouples has not been extensive, it is believed that the best of these, when calibrated at intervals of $50^{\circ} \mathrm{C}$ or less, and used in conjunction with table 1 , will give results which are in error by less than 1 microvolt. This limit of error is given on the basis of one thermojunction; for a multiple-junction instrument it will be larger. The effect of inhomogeneities in thermocouple wire, methods of testing the wire, the construction of multiple-junction thermocouples, and general technique of thermoelectric measurements have been treated in detail by White. ${ }^{11}$ $\mathrm{He}$ is principally concerned with thermocouples for use in calorimetry at moderate temperatures, but a great deal of the technique is applicable to low-temperature work.

If the emf of a thermocouple is observed at three temperatures, about $-70^{\circ},-140^{\circ}$, and $-190^{\circ} \mathrm{C}$, the deviation curve can, as a rule, be drawn so as not to be in error at intermediate temperatures, in the range $0^{\circ}$ to $-190^{\circ} \mathrm{C}$, by as much as 2 microvolts. The relation

$$
E=a t+b t^{2}+c t^{3},
$$

with constants calculated from observed emf at the above temperatures, will give results almost as accurate, but the method of using table 1 , together with a deviation curve, is to be preferred, both because it is more convenient, and also because any serious error of calibration is strikingly evident as an irregularity in the deviation curve.

If a thermocouple is to be used only in the range $0^{\circ}$ to $-90^{\circ} \mathrm{C}$ and an accuracy of \pm 2 microvolts is sufficient, a single calibration in subliming carbon dioxide is adequate. The deviation curve in this case is, of course, a straight line through the observed point and the origin. For most thermocouples a calibration accurate to \pm 2 microvolts is all that is justified, because inhomogeneities in the wires are likely to introduce larger errors.

If the thermocouple is calibrated at the oxygen boiling point, as well as at the $\mathrm{CO}_{2}$ point, a temperature-emf relation, having a maximum error of less than 4 microvolts at temperatures between the $\mathrm{CO}_{2}$ and oxygen points, may be obtained. The deviation curve should approximate a parabola, having its greatest curvature at the low-temperature end. If the deviation curve is found to be nearly linear, the maximum error will be considerably less than 4 microvolts. Wiebe and Brevoort ${ }^{12}$ state that the deviation curve for a copperconstantan thermocouple calibrated at these two temperatures can be represented by the quadratic equation

$$
\text { Deviation }=a E+b E^{2} \text {, }
$$

with an accuracy of about $0.05^{\circ} \mathrm{C}(0.8$ to $2.0 \mu \mathrm{v})$. Adams' table was used as the basis of reference. They base their conclusion on calibrations of seven thermocouples of their own and one from another laboratory. Their somewhat smaller limit of error may probably be explained by the fact that the constantan of their thermocouples was not obtained from as great a number of sources as that of the thermocouples sent to this laboratory for calibration, hence they did not find quite as great a variation in the shapes of the deviation curves.

11 Walter P. White, J. Am. Chem. Soc. 36, 2292 (1914): Rev. Sci. Instr. 4, 142 (1933).

12 Rev. Sci. Instr. 2, 450, (1931).

$259104-40-6$ 
A thermocouple used only at low temperatures should be expected to maintain its calibration better than one subjected to temperatures which accelerate physical and chemical changes in the metals. Giauque and Egan, ${ }^{13}$ and Stephenson and Giauque ${ }^{14}$ have checked some copper-constantan thermocouples several years after their original calibration. They find some discrepancies at temperatures between $-190^{\circ}$ and $-260^{\circ} \mathrm{C}$, but above $-190^{\circ} \mathrm{C}$ no change in calibration of as much as $0.05^{\circ} \mathrm{C}$ was found. Aston ${ }^{15}$ reports a somewhat similar experience, with evidence that the changes observed at very low temperatures were due to repeated cooling of the thermocouples. His results also indicate that, at temperatures above $-200^{\circ} \mathrm{C}$, a copper-constantan thermocouple will not change its calibration by more than $0.05^{\circ} \mathrm{C}$ over a period of several years.

\section{SUMMARY}

Thermocouples sent to the National Bureau of Standards for calibration at low temperatures are compared with a standard platinum-resistance thermometer in a bath of uniform and constant temperature. The emf-temperature relation over an extended range is obtained by measuring the emf at a few selected temperatures and plotting the deviations from the values in a standard table. Deviation curves of a number of copper-constantan thermocouples from different sources indicate that, if the demand for accuracy is not too exacting, two points, the $\mathrm{CO}_{2}$ sublimation temperature and the oxygen boiling point, may be used to obtain a calibration covering the range $0^{\circ}$ to $-190^{\circ} \mathrm{C}$. Thus a fair calibration may be obtained even though a platinum-resistance thermometer and its accessory apparatus are not available. Furthermore, the apparatus used to attain the fixed temperature is not complicated. This is particularly true of the apparatus and material required for the $\mathrm{CO}_{2}$ points. Ordinary commercial solid carbon dioxide is used, and the apparatus consists of a Dewar flask, an electric heating coil, and a barometer for determining the pressure. This calibration at the temperature of subliming $\mathrm{CO}_{2}$ is sufficient to establish the temperature-emf relation from $0^{\circ} \mathrm{C}$ to $-90^{\circ} \mathrm{C}$ with an accuracy of \pm 2 microvolts. It should be remembered that unless considerable care is taken in selecting the constantan wire, errors due to inhomogeneity may be larger than errors of observation. Thus the quality of the thermocouples may not justify the highest accuracy of calibration, and the simpler method of using one or two fixed points may be entirely adequate.

Washington, July 13, 1940.

13 J. Chem. Phys. 5, 45 (1937).

14 J. Chem. Phys. 5, 149 (1937)

15 Abstracts of papers presented at the meeting of the Am. Chem. Soc. at Boston, Mass., September 11 to 15, 1939. Published by the Division of Physical and Inorganic Chemistry. 